INTERVENTIONAL CARDIOLOGY AND SURGERY

\title{
Role of oral rapamycin to prevent restenosis in patients with de novo lesions undergoing coronary stenting: results of the Argentina single centre study (ORAR trial)
}

\author{
A E Rodríguez, M Rodríguez Alemparte, C F Vigo, C Fernández Pereira, C Llauradó, \\ D Vetcher, A Pocovi, J Ambrose
}

See end of article for authors' affiliations

Correspondence to: Dr Alfredo E Rodriguez Cardiac Unit, Otamendi Hospital, Azcuénaga 870, Buenos Aires, Argentina C1115 AAB; centroceci@ sion.com

Accepted 27 January 2005 Published Online First 17 March 2005

\begin{abstract}
Objective: To assess the role of oral rapamycin in the prevention of coronary restenosis in patients undergoing coronary stenting.

Methods: From December 2001 through February 2003, 76 patients with 103 de novo lesions treated percutaneously with bare stents received a loading dose of oral rapamycin $6 \mathrm{mg}$ followed by a daily dose of $2 \mathrm{mg}$ during 28 days in phase I (49 arteries in 34 patients) and $2 \mathrm{mg} /$ day plus $180 \mathrm{mg} /$ day of diltiazem in phase II (54 arteries in 42 patients). Rapamycin blood concentrations were measured in all patients. A six month follow up angiogram was performed in $82.5 \%$ (85 of 103 arteries). Follow up angiographic binary restenosis (>50\%), target vessel revascularisation, late loss, treatment compliance, and major adverse cardiovascular events were analysed and correlated with rapamycin concentrations. Results: Rapamycin was well tolerated and only three patients discontinued the treatment for mild side effects. Angiographic restenosis was found in 15\% of the arteries with angiographic restudy (13 of 85). The target vessel had been revascularised at follow up in $13.6 \%$ of the 103 vessels initially treated (14 of 103 ) and in $18.4 \%$ of the 76 patients (14 of 76). In-stent restenosis in phase I was $19 \%$ compared with $6.2 \%$ in phase II $(p=0.06)$. Angiographic in-stent restenosis in lesions of patients with rapamycin blood concentrations $\geqslant 8 \mathrm{ng} / \mathrm{ml}$ was $6.2 \%$ and with rapamycin concentrations $<8 \mathrm{ng} / \mathrm{ml}$ was $22 \%$ ( $p=0.041)$. Late loss was also significantly lower when rapamycin concentrations were $\geqslant 8 \mathrm{ng} / \mathrm{ml}$ $(0.6 \mathrm{~mm} v 1.1 \mathrm{~mm}, \mathrm{p}=0.031)$. A Pearson test showed a linear correlation between follow up late loss and rapamycin blood concentration $(r=-0.826, p=0.008)$.

Conclusion: Oral rapamycin administered for one month after percutaneous coronary intervention was safe and with few minor side effects. High rapamycin blood concentrations were associated with significantly lower late loss and angiographic in-stent restenosis.
\end{abstract}

D ata on the use of systemic rapamycin in animals have shown a significant reduction of neointimal hyperplasia. ${ }^{1}$ Clinical studies have shown an association between rapamycin eluting stents and low rates of restenosis compared with bare stents in both observational and randomised trials. ${ }^{2-5}$ Even though the restenosis rate was significantly lower, coated stents cost more than conventional stents and the long term data of these eluting stents need to be addressed. ${ }^{6}$

Rapamycin (Rapamune, sirolimus), a natural macrocyclic lactone, is a potent immunosuppressive agent that was developed by Wyeth-Ayerst Laboratories (Madison, New Jersey, USA) and is given orally to renal transplant patients to avoid acute or chronic rejection. ${ }^{78}$

Although this drug is taken long term by renal transplant recipients, few side effects have been reported. ${ }^{8}$ The role of oral rapamycin in the prevention of angiographic restenosis in patients undergoing coronary stent implantation is not well known; furthermore, the dose-response relation is not well established.

We previously reported preliminary data suggesting that high blood concentration of the drug may be associated with better angiographic follow up results; however, those findings were too preliminary and from a non-homogeneous population (de novo and in-stent restenosis lesions) and with no significant evidence. ${ }^{9}$
Recently, a pilot study also reported encouraging data with oral administration of rapamycin. ${ }^{10}$ The purpose of the present prospective study was to assess the role of oral rapamycin in the prevention of coronary restenosis in de novo lesions in patients undergoing coronary stenting after percutaneous coronary intervention (PCI).

\section{METHODS}

\section{Patient population and study design}

From December 2001 though February 2003, 76 patients with a clinical indication for PCI for a novo lesion were included in this protocol. The procedures were performed in the cardiac catheterisation laboratories of Otamendi Hospital in Buenos Aires, Argentina.

Among these 76 patients, 109 bare coronary stents were deployed in 103 de novo lesions in an equal number of major native epicardial vessels. Patients with in-stent restenosis, bifurcation lesions, vein graft lesions, lesion length $>20 \mathrm{~mm}$, acute myocardial infarction in the previous 72 hours, poor left ventricular function (ejection fraction $<35 \%$ ), renal failure defined as creatinine concentration

Abbreviations: $\mathrm{CACl}$, Argentina Society for Cardiac Interventions; MACE, major adverse cardiovascular events; MLD, minimum luminal diameter; $\mathrm{PCl}$, percutaneous coronary intervention; ORBIT, oral Rapamune to inhibit restenosis 
$>2 \mathrm{mg}$, or under immunosuppressive treatment were excluded from the study. In phase I, rapamycin (Rapamune, Wyeth Laboratories) was given orally as a loading dose of $6 \mathrm{mg}$ followed by a daily dose of $2 \mathrm{mg} /$ day for 28 days, starting immediately after successful stent deployment.

In phase II, a daily dose of $180 \mathrm{mg}$ of diltiazem was added; diltiazem used together with oral rapamycin in renal transplant patients has been associated with high therapeutic blood concentration of rapamycin and lower side effects. ${ }^{11}{ }^{12}$ It has been shown that coadministration of a single dose of diltiazem with rapamycin leads to higher rapamycin exposure. The mean whole blood rapamycin area under the plasma concentration in time curve increased $60 \%$ and maximum concentration increased $43 \%$. Coadministration also decreased the renal clearance of rapamycin, presumably by inhibiting the first pass metabolism of rapamycin. ${ }^{12}$ Rapamycin blood concentrations were measured in all patients in the same central core laboratory ${ }^{9}$ after the third week of treatment in phase I. As the immunosuppressive effect of the drug has been shown to be optimal within four days after treatment, in phase II blood concentration was measured during the first week. ${ }^{7}$

According to our previous experience, high rapamycin blood concentration was predefined as $\geqslant 8 \mathrm{ng} / \mathrm{ml}{ }^{9}$

A lipid profile (cholesterol, high density lipoprotein, low density lipoprotein, and triglycerides) and complete blood count were determined before and after four weeks of treatment for all patients. A personal clinical interview was required of all patients each week for the first month of treatment and thereafter monthly for the six month clinical follow up. Statins were given long term independently of lipid profile. Clopidogrel was prescribed for six months to all patients.

Procedural and six month angiographic follow up data were analysed by quantitative coronary angiography by a central core laboratory on a MEDIS computerised system. ${ }^{13}$

Angiographic binary restenosis ( $>50 \%$ in the target lesion in the follow up angiogram), minimum luminal diameter (MLD), late loss (the difference between the immediate postPCI MLD and the follow up MLD), and net gain (the difference between the follow up MLD and the pre-PCI MLD) were recorded.

\section{End points}

The primary end point of the study was to correlate angiographic binary restenosis and late loss at the follow up angiogram with the blood concentration of the drug measured during the first month of treatment. Net gain and MLD were also recorded. The relation between rapamycin blood concentration and adverse side effects was analysed as a safety end point.

Target vessel revascularisation, target lesion revascularisation, and major adverse cardiovascular events (MACE) during the first year of follow up were also recorded. MACE was defined as death, myocardial infarction, stroke, and repeat revascularisation procedures. Target lesion revascularisation was performed at follow up when the residual stenosis was $>50 \%$ and myocardial revascularisation was clinically indicated.

Various stents designs were implanted: BX Velocity and Crossflex (Johnson \& Johnson), Express (Boston Scientific), S7 (Medtronic AVE), and Carbostent (Sorin Biomedica). After predilatation of the target lesion, stents were deployed at high pressure $(>13 \mathrm{~atm}$ ) guided by online quantitative coronary angiography. Stent length was $<12 \mathrm{~mm}$ in 30 lesions, $>12 \mathrm{~mm}$ in 70 , and $>20 \mathrm{~mm}$ in nine. All patients received aspirin ( $325 \mathrm{mg}$ /day indefinitely) and a loading dose of clopidogrel $300 \mathrm{mg}$ on the day of the procedure and $75 \mathrm{mg}$ / day thereafter for six months.

The protocol was approved by the medical and ethics committee of Otamendi Hospital and by the steering committee of the Argentina Society for Cardiac Interventions (CACI). During the study an independent safety monitoring committee from CACI adjudicated the adverse events. Written informed consent was obtained from all patients.

\section{Statistical analysis}

Continuous variables were expressed as mean (SD). Pre- and postintervention data and postintervention and follow up data were compared by a two tailed paired $t$ test. Groups were compared by the unpaired Student's $t, \chi^{2}$, or Fisher's exact tests as appropriate. Rapamycin concentrations and the amount of late loss at follow up were compared by linear regression analysis (Pearson test). Multivariate logistic regression analysis was used to identify independent predictors of angiographic restenosis at follow up. A probability value of $\mathrm{p}<0.05$ was considered significant.

\section{RESULTS}

Table 1 presents baseline demographic, clinical, and angiographic characteristics of the patients. The mean (SD) age was 63 (12) years. More than $60 \%$ of patients presented with unstable angina; $20 \%$ were diabetic, $23 \%$ had a previous AMI, and more than $80 \%$ had class $\mathrm{B}$ or $\mathrm{C}$ lesions according to the American College of Cardiology/American Heart Association classification modified by Ellis et al. ${ }^{14}$ In phase II after the first week of treatment, five patients who did not reach a sufficient blood concentration of the drug received an additional $1 \mathrm{mg}$ of oral rapamycin ( $3 \mathrm{mg}$ daily) plus diltiazem.

\section{Hospital and 30 day results}

All stents were deployed successfully. One patient, in whom two vessels were treated with stents, developed subacute artery closure a few hours after the procedures and was retreated with PCI and a stent. This patient developed an acute myocardial infarction, which was the only adverse event during hospitalisation in this cohort of patients. The average lesion length was $10.6(0.9) \mathrm{mm}$.

During the first month, 19 patients $(25 \%)$ had minor side effects (table 2 ), six patients in phase I ( $18 \%$ ) and 13 in phase II $(31 \%, p=0.436)$. Only three discontinued the medication $(3.9 \%)$, one in phase I and two in phase II. As table 2 shows, the most frequent side effects were diarrhoea $(7.8 \%)$ and skin rash $(9.2 \%)$. There were no changes in white cell count or cholesterol concentration relative to baseline, whereas triglyceride concentrations tended to be higher than at baseline, before rapamycin treatment was started $(p=0.09)$. Ninety per cent of the side effects of rapamycin occurred within the first week of treatment and were insignificantly higher in phase II than in phase I $(p=0.436)$. Rapamycin blood concentration was significantly higher in phase II than in phase I (9.3 (2.6) ng/ml $v 6.2$ (2.9) $\mathrm{ng} / \mathrm{ml}, \mathrm{p}=0.0002$ ).

\section{Late clinical and angiographic follow up}

Clinical follow up was obtained for all patients during one year after PCI. Angiographic follow up 6.8 (1.1) months after the procedure was available for $82 \%$ of the arteries treated ( 85 of 103 ), $90 \%$ in phase I (44 of 49 ) and $76 \%$ (4l of 54) in phase II.

Of the 103 target vessels initially treated $14 \%$ (14 of 103) had been revascularised at follow up (including in-hospital emergency procedures) in $18 \%$ of the 76 patients ( 14 of 76 ), nine of 34 patients in phase I (26\%) and five of 42 patients in 
Table 1 Baseline demographic, clinical, and angiographic characteristics of the global population and according to rapamycin blood concentration

\begin{tabular}{|c|c|c|c|c|}
\hline & \multirow[b]{2}{*}{ Overall } & \multicolumn{2}{|c|}{ Rapamycin concentration } & \multirow[b]{2}{*}{$p$ Value } \\
\hline & & $\geqslant 8 \mathrm{ng} / \mathrm{ml}$ & $<8 \mathrm{ng} / \mathrm{ml}$ & \\
\hline Patients & $n=76$ & $n=44$ & $n=32$ & \\
\hline Women & $6(8 \%)$ & $2(4.5 \%)$ & $4(12.5 \%)$ & NS \\
\hline Hypertension & $47(62 \%)$ & $23(52 \%)$ & $24(75 \%)$ & NS \\
\hline High cholesterol & $47(62 \%)$ & $28(64 \%)$ & $19(59 \%)$ & NS \\
\hline Diabetes & $15(20 \%)$ & $5(11.3 \%)$ & $10(31 \%)$ & NS \\
\hline Current smoking & $18(24 \%)$ & $124(27 \%)$ & $6(19 \%)$ & NS \\
\hline Previous AMl & $17(22.3 \%)$ & $10(23 \%)$ & $7(22 \%)$ & NS \\
\hline Unstable angina IIB, IIIB, C & $52(68.4 \%)$ & $29(66 \%)$ & $24(75 \%)$ & NS \\
\hline Arteries & $\mathrm{n}=103$ & $\mathrm{n}=58$ & $\mathrm{n}=45$ & \\
\hline \multicolumn{5}{|l|}{ ACC/AHA morphology } \\
\hline Type A & $16(16 \%)$ & $8(14 \%)$ & $8(18 \%)$ & NS \\
\hline Type B1 & $28(27 \%)$ & $15(26 \%)$ & $13(29 \%)$ & NS \\
\hline Type B2 & $29(28 \%)$ & $17(29 \%)$ & $12(27 \%)$ & NS \\
\hline Type C & $30(29 \%)$ & $18(31 \%)$ & $12(27 \%)$ & NS \\
\hline LMCA & $6(6 \%)$ & $4(7 \%)$ & $2(4.4 \%)$ & NS \\
\hline LAD & $57(55 \%)$ & $32(55 \%)$ & $25(56 \%)$ & NS \\
\hline LCX & $23(22 \%)$ & $12(21 \%)$ & $12(27 \%)$ & NS \\
\hline RCA & $17(17 \%)$ & $10(17 \%)$ & $6(13 \%)$ & NS \\
\hline
\end{tabular}

ACC, American College of Cardiology; AHA, American Heart Association; AMI, acute myocardial infarction; LAD, left anterior descending coronary artery; LCX, left circumflex artery; LMCA, left main coronary artery; NS, not significant; RCA, right coronary artery.

phase II $(12 \%, p=0.23)$. During the one year of follow up, including in-hospital events, MACE occurred in 15 of 76 of patients (20\%): 13 target vessel revascularisations, one repeat PCI and stenting in a non-target vessel, and one myocardial infarction (this patient also had an emergency PCI after the initial procedure).

Angiographic binary restenosis was found in 15\% (13 of 85) of the arteries followed up by angiography. In-segment restenosis was $22 \%$ in phase I versus $10 \%$ in phase II $(\mathrm{p}=0.221)$, whereas in-stent restenosis in phase II tended to be lower than in phase I $(6.2 \% v 19 \%, \mathrm{p}=0.066)$.

\section{Restenosis and rapamycin blood concentrations}

Table 3 shows quantitative coronary angiography data of the 85 lesions followed up angiographically. At follow up the MLD of lesions in patients with a high rapamycin blood concentration $(>8 \mathrm{ng} / \mathrm{ml})$ was significantly larger than in those with lower concentrations of the drug $(\mathrm{p}=0.05)$. The analysis of late loss (fig 1) and net gain with rapamycin concentrations also showed a significant difference in favour of lesions of patients with high rapamycin concentrations (late loss was $0.6 \mathrm{~mm} v 1.1 \mathrm{~mm}, \mathrm{p}=0.03 \mathrm{l}$, net gain $1.4 \mathrm{~mm}$ $v 1.0 \mathrm{~mm}, \mathrm{p}=0.021$ ). Angiographic binary in-stent restenosis was also significantly lower in the group with rapamycin concentrations $>8 \mathrm{ng} / \mathrm{ml} \quad(6.2 \% \quad v \quad 22 \%$, $\mathrm{p}=0.041$ ) (table 3). Furthermore, a Pearson test showed a linear correlation between late loss at follow up and rapamycin blood concentration $(r=-0.826, \mathrm{p}=0.008)$

\begin{tabular}{ll}
$\begin{array}{l}\text { Table } 2 \text { Adverse reactions during the first } \\
\text { month of treatment of } 76 \text { patients }\end{array}$ \\
\hline Diarrhoea & $6(7.8 \%)$ \\
Vomiting & $1(1.3 \%)$ \\
Constipation & $2(2.6 \%)$ \\
Gastritis & $1(1.3 \%)$ \\
Mouth ulceration & $4(5.2 \%)$ \\
Skin rash & $7(9.2 \%)$ \\
Fever & $2(2.6 \%)$ \\
Insomnia & $1(1.3 \%)$ \\
Headache & $1(1.3 \%)$ \\
Overall & $19(25 \%)$ \\
Drug discontinuation & $3(3.9 \%)$ \\
\hline
\end{tabular}

(fig 2). Multivariate logistic regression analysis identified that reference vessel size $(-2.206(0.83), \mathrm{p}<0.008)$ and rapamycin blood concentration $(-0.243, \mathrm{p}<0.036)$ were the only independent predictors of angiographic restenosis at follow up.

We used $>8 \mathrm{ng} / \mathrm{ml}$ as cut off because visual analysis of the rapamycin blood concentrations and late loss suggested this to be the proper cut off.' This number gave us a significant difference between the groups (above or below 8). Constructing a receiver operating characteristic curve, which is not visual but quantitative analysis, also showed that a rapamycin blood concentration of $8 \mathrm{ng} / \mathrm{ml}$ was the proper cut off. Furthermore, the mean rapamycin blood concentration in patients with no restenosis was $7.9 \mathrm{ng} / \mathrm{ml}$.

\section{DISCUSSION}

In this observational study, oral rapamycin treatment during the first month after stent deployment was safe, usually well tolerated, and without major side effects. In the lesions of patients with high rapamycin blood concentrations, late loss, net gain, and binary in-stent restenosis were significantly better at the 6.8 month follow up angiogram than in lesions of patients with lower drug concentrations. Furthermore, we showed for the first time a linear correlation between late loss

Table 3 Baseline (103 arteries) and follow up quantitative coronary angiography ( 85 arteries) data

\begin{tabular}{|c|c|c|c|}
\hline & \multicolumn{2}{|c|}{ Rapamycin blood concentration } & \multirow[b]{2}{*}{ p Value } \\
\hline & $\begin{array}{l}\geqslant 8 \mathrm{ng} / \mathrm{ml} \\
(\mathrm{n}=48)\end{array}$ & $\begin{array}{l}<8 \mathrm{ng} / \mathrm{ml} \\
(\mathrm{n}=37)\end{array}$ & \\
\hline Lesion length $(\mathrm{mm})$ & $10.2(0.7)$ & $10.7(0.6)$ & NS \\
\hline Reference diameter $(\mathrm{mm})$ & $3.0(0.49)$ & $3.15(0.48)$ & NS \\
\hline MLD pre $(\mathrm{mm})$ & $0.79(0.41)$ & $0.70(0.40)$ & NS \\
\hline MLD post $(\mathrm{mm})$ & $2.79(0.48)$ & $2.9(0.50)$ & NS \\
\hline MLD follow up (mm) & $2.16(0.62)$ & $1.71(0.59)$ & 0.05 \\
\hline Late loss (mm) & $0.6090 .56)$ & $1.1(0.61)$ & 0.031 \\
\hline Net gain (mm) & $1.4(0.61)$ & $1.0(0.63)$ & 0.021 \\
\hline In-stent restenosis & $6.2 \%$ & $22 \%$ & 0.041 \\
\hline In-segment restenosis & $10.4 \%$ & $22 \%$ & NS \\
\hline
\end{tabular}




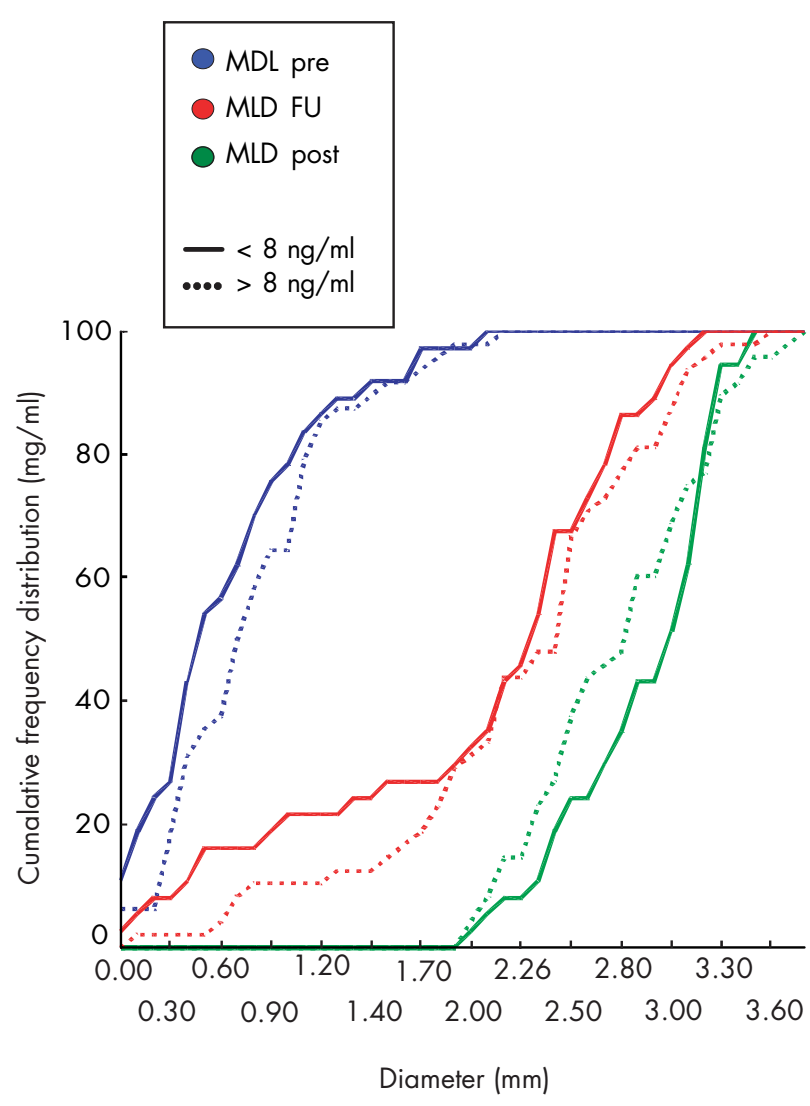

Figure 1 Cumulative distribution functional curves of minimum luminal diameter (MLD) of lesions in patients with rapamycin blood concentrations $<8 \mathrm{ng} / \mathrm{ml}$ and $>8 \mathrm{ng} / \mathrm{ml}$ before (pre) and immediately after (post) percutaneous coronary intervention and during follow up (FU). Late loss $p=0.031$ in favour of $>8 \mathrm{ng} / \mathrm{ml}$.

at follow up and rapamycin blood concentration during the first month of treatment.

The cytostatic and anti-inflammatory effects of rapamycin were reported previously from preclinical and clinical studies. ${ }^{17815}$ Rapamycin's effects on the inhibition of smooth muscle cell proliferation were previously reported several years ago in animal studies. ${ }^{1}$ Recently, other rapamycin-like drugs were reported in animal studies to have similar effects against neointimal growth after stenting with systemic treatment. ${ }^{16}$

The introduction of rapamycin eluting stents during PCI was one of the major breakthroughs of this decade in interventional procedures. Several observational and randomised studies have shown a significantly lower restenosis rate with these drug eluting stents than with standards stents. ${ }^{2-5}{ }^{17}$ The possibility of adverse side effects and the need to achieve therapeutic concentrations locally at the site of PCI were the major concerns with the systemic use of this drug. In contrast, high local concentrations of the drug and low systemic blood concentrations would be major advantages of the rapamycin coated stent. One non-randomised small trial of oral rapamycin treatment of patients with recalcitrant instent restenosis reported poor tolerance to the oral administration of the drug and a high restenosis rate. ${ }^{18}$ In that study, the authors ${ }^{18}$ studied only 22 patients; among these, previous radiation therapy had failed in 20 patients (91\%) and only $50 \%$ of the cohort completed the oral rapamycin treatment. The efficacy of drug eluting stents for the same population was not established. Furthermore, poor results were reported for implantation of rapamycin drug eluting stents in patients with failed vascular brachytherapy, some

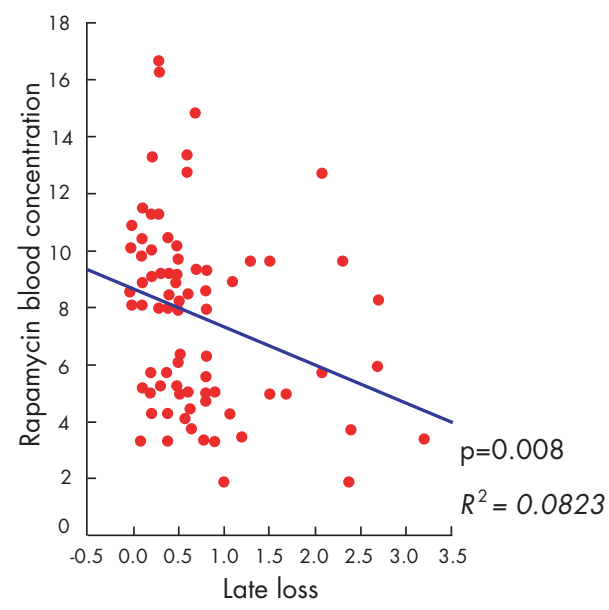

Figure 2 Pearson test between late loss and rapamycin blood concentration.

associated with thrombosis and high rate of restenosis. ${ }^{19}$ Recently, a randomised, double blind, placebo controlled study reported a significant reduction in binary restenosis and late loss in patients with in-stent restenosis treated with a preloading dose of oral rapamycin. ${ }^{20}$ In this study, similar to our experience, rapamycin blood concentration during the first day after the procedure was linearly correlated with late loss at follow up. In that study, with a different patient population, a preloading dose of rapamycin was started 48 hours before PCI. Rapamycin immunosuppressive effects after oral administration were optimal after four days of treatment. $^{7}$ Perhaps, with a population at high risk for restenosis such as patients with in-stent restenosis, ${ }^{20}$ a prePCI loading dose would provide better results. However, in our study, oral rapamycin given at the time of the procedure resulted in a single digit restenosis rate on follow up when an appropriate blood concentration of the drug was obtained. Furthermore, it is unknown whether the antiproliferative and immunosuppressive effects of rapamycin occur simultaneously or whether the antiproliferative effects begin earlier.

The ORBIT (oral Rapamune to inhibit restenosis) pilot trial recently reported a single digit restenosis rate with oral rapamycin. When $2 \mathrm{mg} /$ day was used as a maintenance dose, $40 \%$ of patients experienced minor or moderate side effects. ${ }^{10}$

Lastly, even though the amount of late loss reported with drug eluting stents $\mathrm{s}^{2-5} 17$ is lower than that presented here, the proper late loss cut off has not been established. How the cut off correlates with the late safety outcome of these devices remains unclear. ${ }^{621}$

The results of our study of an oral dose of rapamycin after coronary stent implantation confirmed our preliminary report. ${ }^{9}$ High rapamycin blood concentrations are associated with significantly lower angiographic restenosis and late loss with larger net gain and MLD at follow up without significant incremental risk of adverse effects. Lastly, we report a strong correlation between late loss and rapamycin blood concentration.

\section{Limitations}

This was an observational, non-randomised study in a group of patients with a follow up angiogram at six months. It is unknown whether these findings will be maintained during more prolonged follow up. Furthermore, the optimal dose, the need for pretreatment, and the duration of oral treatment have not been determined.

Minor side effects were present in $26 \%$ of the patients and these numbers could have been underestimated because of the small sample size. We did not analyse other complex 
subsets of lesions such as in small vessels, in-stent restenosis, long lesions, and diabetes and they should be investigated further.

\section{Conclusion}

These encouraging findings show a role for oral rapamycin in the prevention of angiographic restenosis in de novo lesions after PCI. A randomised double blind, placebo controlled trial in de novo lesions is in progress (ORAR II).

\section{ACKNOWLEDGEMENTS}

Thanks to the Argentina Society for Cardiac Interventions (CACI).

\section{Authors' affiliations \\ A E Rodríguez, M Rodríguez Alemparte, C F Vigo, C Fernández}

Pereira, C Llauradó, Cardiac Unit, Otamendi Hospital, Buenos Aires

School of Medicine, Buenos Aires, Argentina

D Vetcher, A Pocovi, Argentina Society for Cardiac Interventions (CACl), Buenos Aires, Argentina

J Ambrose, Cardiac Unit, Saint Vincent Hospital, New York, New York, USA

No authors have any financial associations that may pose a conflict of interest in connection with this manuscript.

\section{REFERENCES}

1 Gallo R, Padurean A, Jayaraman T, et al. Inhibition of intimal thickening after balloon angioplasty in porcine coronary arteries by targeting regulators of the cell cycle. Circulation 1999;99:2164-70.

2 Sousa JE, Costa MA, Abizaid A, et al. Lack of neointimal proliferation after implantation of sirolimus-coated stents in human coronary arteries. Circulation 2001;103:192-5.

3 Morice MC, Serruys PW, Sousa JE, et al. A randomized comparison of sirolimus-eluting stent with a standard stent of coronary revascularization. N Engl J Med 2002;346:1773-80.

4 Moses JW, Leon MB, Popma JJ, et al. Sirolimus eluting stents versus standard stents in patients with stenosis in a native coronary artery. N Engl J Med 2003;349:1315-23.
5 Lemos PA, Saia F, Lightart JM, et al. Coronary restenosis after sirolimus eluting stent implantation: morphological description and mechanistic analysis from a consecutive series of cases. Circulation 2003;108:257-60.

6 Virmani R, Guagliumi G, Farb A, et al. Localized hypersensitivity and late coronary thrombosis secondary to a sirolimus-eluting stent: should we be cautious? Circulation 2004; 109:701-5.

7 Groth CG, Backman L, Morales JbM, et al. Sirolimus (rapamycin)-based therapy in human renal transplantation. Transplantation 1997;67:1036-42.

8 Johnson RW, Kreis H, Oberbauer R, et al. Sirolimus allows early cyclosporine withdrawal in renal transplantation resulting in improved renal function and lower blood pressure. Transplantation $2001 ; 72: 777-86$.

9 Rodriguez A, Rodriguez Alemparte M, Vigo C, et al. Pilot study of oral rapamycin to prevent restenosis in patients undergoing coronary stent therapy: Argentina single center study. J Invas Cardiol 2003;15:581-4.

10 Waksman R, Ajani A, Pichard A, et al. Oral rapamycin to inhibit restenosis after stenting of de novo coronary lesions: the oral rapamune to inhibit restenosis (ORBIT) study. J Am Coll Cardiol 2004;44:1386-92.

11 Groth CG, Backman L, Morales JM, et al. Sirolimus (rapamycin)-based therapy in human renal transplantation: similar efficacy and different toxicity compared with cyclosporine. Sirolimus European renal transplantation study group. Tansplantation 1999;67:1036-42.

12 Bottiger Y, Sawe J, Brattstrom C, Pharmacokinetic interaction between single oral dose of diltiazem and sirolimus in healthy volunteers, et al. Clin Pharmacol Ther 2001;69:32-40.

13 Rodriguez A, Santaera $O$, Larribau $M$, et al. Coronary stenting decreases restenosis in lesions with early loss in luminal diameter 24 hours after successful PTCA. Circulation 1995;91:1397-402.

14 Ellis S, Vandormael M, Cowley M, et al. Coronary morphologic and clinical determinants of procedures outcome with angioplasty for multiple vessels coronary disease. Circulation 1990;82:1193-202.

15 Poon M, Marx SO, Gallo R, et al. Rapamycin inhibits vascular smooth muscle cell migration. J Clin Invest 1996;98:2277-83.

16 Farb A, Jhon M, Acampado E, et al. Oral everolimus inhibits in-stent neointimal growth. Circulation 2002;106:2379.

17 Stone G, Ellis S, Cox D, et al. A polymer-based paclitaxel-eluting stent in patients with coronary artery disease. N Engl J Med 2004;350:221-31.

18 Brara P, Moussavian M, Grise M, et al. Pilot trial of oral rapamycin for recalcitrant restenosis. Circulation 2003;107:1722-4.

19 Degertekin M, Regar E, Tanabe K, et al. Sirolimus eluting stent for treatment of complex in stent restenosis. J Am Coll Cardiol 2003;41:184-9.

20 Hausleiter J, Kastrati A, Mehilli J, et al. Randomized, double blind, placebo controlled trial of oral sirolimus for restenosis prevention in patients with in stent restenosis: the oral sirolimus to inhibit recurrent in stent stenosis trial (OSIRIS). Circulation 2004;110:790-5.

21 McFadden E, Stabile E, Regar E, et al. Late thrombosis in drug-eluting coronary stents after discontinuation of antiplatelet therapy. Lancet 2004;364:1419-21.

\section{IMAGES IN CARDIOLOGY}

\section{Perils of polypectomy}

A 61 year old woman undergoing nasal polypectomy developed hypotension and ST elevation in the inferior leads on ECG. She was previously well with no risk factors for ischaemic heart disease. Troponin I was raised at $3.5 \mathrm{ng} / \mathrm{ml}$. Coronary angiography revealed a normal left system with diffuse spasm of the right coronary artery (panel A). This resolved completely with the administration of intracoronary glyceryl trinitrate (panel B).

The nasal pack inserted at the time of nasal polypectomy contained Brompton's solution (cocaine hydrochloride $15 \mathrm{~g} \mathrm{(3 \% ),}$ adrenaline (epinephrine) (1 in 1000) $125 \mathrm{ml}$, potassium sulphate $2.5 \mathrm{~g}$, and phenol $1.2 \mathrm{~g}$ in $500 \mathrm{ml}$ purified water). Urinary cocaine metabolites subsequently tested positively. The patient's symptoms settled on removal of the pack and she made an uneventful recovery.

P Collier

M Quinn

doctorcollier@hotmail.com
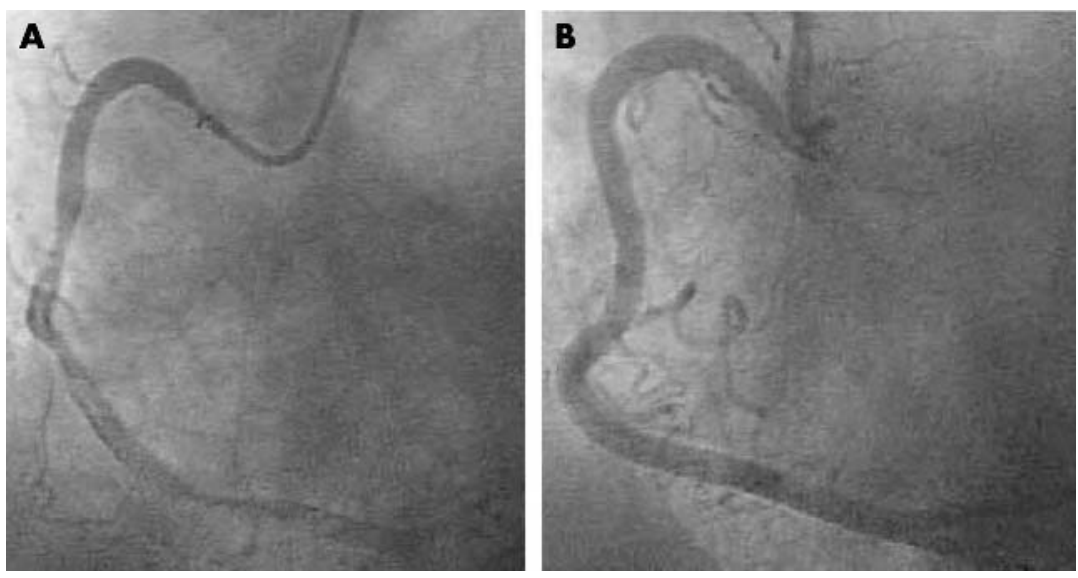

I wish to declare no competing interests. Written consent from the patient was obtained. 